\title{
DISPOSAL OPTIONS FOR DREDGED MARINE SEDIMENTS BASED ON PHYSICOCHEMICAL AND TOXICOLOGICAL CHARACTERIZATION
}

\author{
A. KATSIRI ${ }^{1, *}$ \\ M. PANTAZIDOU ${ }^{2}$ \\ I. DAMIKOUKA ${ }^{1}$ \\ CH. KONTOGIORGI \\ A. TRINGALI ${ }^{1}$
}

\author{
${ }^{1}$ National Technical University of Athens \\ School of Civil Engineering \\ Division of Water Resources and Environmental Engineering \\ 5 Iroon Polytechniou, 15780 Zografou, Greece \\ ${ }^{2}$ National Technical University of Athens \\ School of Civil Engineering, Geotechnical Division \\ 9 Iroon Polytechniou, 15780 Zografou, Greece \\ ${ }^{3}$ Organization of Port of Piraeus \\ 10, Akti Miaouli, 18538 Piraeus, Greece
}

Received: 10/10/07

Accepted: $14 / 12 / 07$ *to whom all correspondence should be addressed: e-mail: akatsiri@central.ntua.gr

\begin{abstract}
This paper presents a methodology of evaluating management options for dredged sediments on the basis of an array of characterization tests and gives an example application for the sediments of Piraeus port. A conceptual model is proposed to guide selection among three management options. The model provides for two tiers of assessment. In tier I, disposal in open sea is evaluated based on a sequence of characterization tests. The final decision is based on the combination of results from chemical and toxicological analyses, supplemented by physical characteristics of sediments. In addition, tier I provides an indication of the need for further characterization of the sediments, in order to determine whether environmental remediation may also be required, independently of dredging activities. Tier II evaluates the other two management options, disposal in landfills or in confined facilities, for the sediments that did not meet tier I requirements for open-sea disposal. Decisions in tier II are facilitated by well-established effluent criteria applied to saltwater and wastes admitted to landfills. The application of the decision-making model for the sediment samples from the port of Piraeus indicated that disposal to open sea is not feasible for the more contaminated sediments from areas with increased shipping activities. Disposal in confined facilities proved a viable option for most of the sediments, whereas all sediments were characterized as non hazardous and can therefore be accepted in an ordinary landfill.
\end{abstract}

KEYWORDS: sediment disposal, dredged material, toxicity, heavy metals, sulfides, simultaneously extracted metals, marine waters, landfills, confined facilities.

\section{INTRODUCTION}

Marine sediments are the ultimate receptor of contaminants from anthropogenic activities, both at sea and on shore. Harbors and coastal areas around most cities worldwide have sediments that are contaminated with heavy metals and organic substances, such as hydrocarbons, polyaromatic hydrocarbons and polychlorinated biphenyls. Metals are attached to different binding phases in the sediment, i.e., carbonates, $\mathrm{Mn}$ and Fe oxides, organic matter, sulfides and silicates. The toxicity of sediments is not influenced by the concentration of total metals, but only by the concentration of the bioavailable fraction of metals. Hence, different sediments exhibit different degrees of toxicity for the same total quantity of a metal. This suggests that the bioavailability of metals in sediments is related to the chemical activity of the metal in the sediment - interstitial water system.

The forces that drive an effort to manage contaminated sediments are (a) dredging in order to meet port and navigation requirements and (b) environmental cleanup required to reduce con- 
tamination levels to a specified level. In Europe, hundreds of million cubic meters of sediment will be dredged every year. An important consideration for any dredging project is the disposal of the dredged material.

This paper presents a methodology of evaluating management options for dredged sediments on the basis of an array of chemical and toxicological characterization tests and gives an example application for the sediments of Piraeus port. Decisions are guided by a conceptual model that helps to structure and organize requirements and information relevant for the environmental management situation. Conceptual models are an essential part of any management process and their application to the management of contaminated sediments has been discussed extensively by Katsiri (2005).

\section{THE CONCEPTUAL MODEL}

The conceptual model used in the decision-making process is shown in Figure 1. The model uses a battery of six characterization tests, arranged in two decision tiers, tier I and tier II, involving measurements of: (1) total metals in sediment, $(2 a)$ metals in pore water, $(2 b)$ toxicity of pore water, (3a) metals in leachate, $(3 b)$ toxicity of leachate and (4) acid volatile sulfides and simultaneously extracted metals in the acid phase of an extraction technique (AVS/SEM). Tests are performed in three matrices: collected sediment, sediment pore water and leachate produced from a standardized leaching test. Three management options are considered: (I) disposal to open sea or other beneficial use, (II) disposal in landfills and (III) disposal in confined facilities, depending primarily on the results of tests (1), (3a) and (3b), respectively.

Tier I first evaluates the chemical characterization of collected sediment samples, in terms of their heavy metal content (test 1). Results are compared to limit values proposed by the Dutch Ministry of Housing, Spatial Planning and the Environment (VROM, 2000). If concentration values are lower than target levels, then management option I can be applied. If concentration values are higher than intervention levels, there is a potential toxicity risk and, hence, land disposal methods may have to be considered. In no clear-cut cases, e.g., when concentration values are between target and intervention levels, the results of three additional tests (tests $2 \mathrm{a}, 2 \mathrm{~b}$ and 4 , which indicate the degree of the bioavailability of the contaminants) are considered as supporting evidence for the management decision.

Although the conceptual model is developed primarily for the disposal of dredged sediments, it can also provide an indication for whether further characterization of the sediments is needed for possible environmental remediation. This is feasible because the logic of the model is consistent with existing decision-making frameworks for sediment remediation, which typically evaluate the two lines of evidence considered herein, sediment chemistry (e.g., test 1) and sediment toxicology (e.g., test 4), as well as a third line of evidence, the structure of the benthic community (Chapman, 1990; Chapman and Anderson, 2005). Following this logic, it is proposed that further sediment characterization is not advised simply if intervention values are exceeded (test 1 ), but only if, in addition, the potential for toxicity is identified (tests 4 and $2 b$ ).

In Tier II, characterization tests $3 \mathrm{a}$ and $3 \mathrm{~b}$ are used as the decision tool for management options II and III. Characterization test $3 a$ is a leaching test based on Council Decision $2003 / 33 / E C$, which establishes criteria in the form of limit values for the acceptance of waste to landfills.

For management option II, landfill disposal, concentration of parametric values in the leachate, expressed in $\mathrm{mg} \mathrm{kg}^{-1}$ (contaminant mass/mass of dry solids), are compared to limit values set in 2003/33/EC. Dredged material is then characterized as inert, non hazardous or hazardous and can be disposed off to the relevant type of landfill.

Management option III, confined storage, is a common method of disposal in many countries. Dredged material is discharged into open confined basins, built onshore, close to the coastline. Solids settle out and consolidate at the bottom, while excess supernatant water is allowed to overflow to the sea, following a suitable initial dilution. The leaching test is used to simulate the quality of the supernatant (test $3 a$ ) and assess its potential risk to marine (and fresh-water) organisms (test 3b) (Palermo, 1986). The concentrations of parametric values in the leachate, expressed in $\mathrm{mg} \mathrm{L}^{-1}$ (contaminant mass/leachate volume), are compared with 
saltwater standards, by means of the dilution required to meet these standards before supernatant is discharged to the environment. If the calculated dilution is unattainable, then such a discharge may prove prohibitive and management option II will be the only option available. The limit value for each metal considered herein is the Criteria Maximum Concentration (CMC) provided by the US Environmental Protection Agency (EPA) as an estimate of the highest concentration of the metal in saltwater to which an aquatic community can be exposed briefly without resulting in an unacceptable effect (USEPA, 2006).

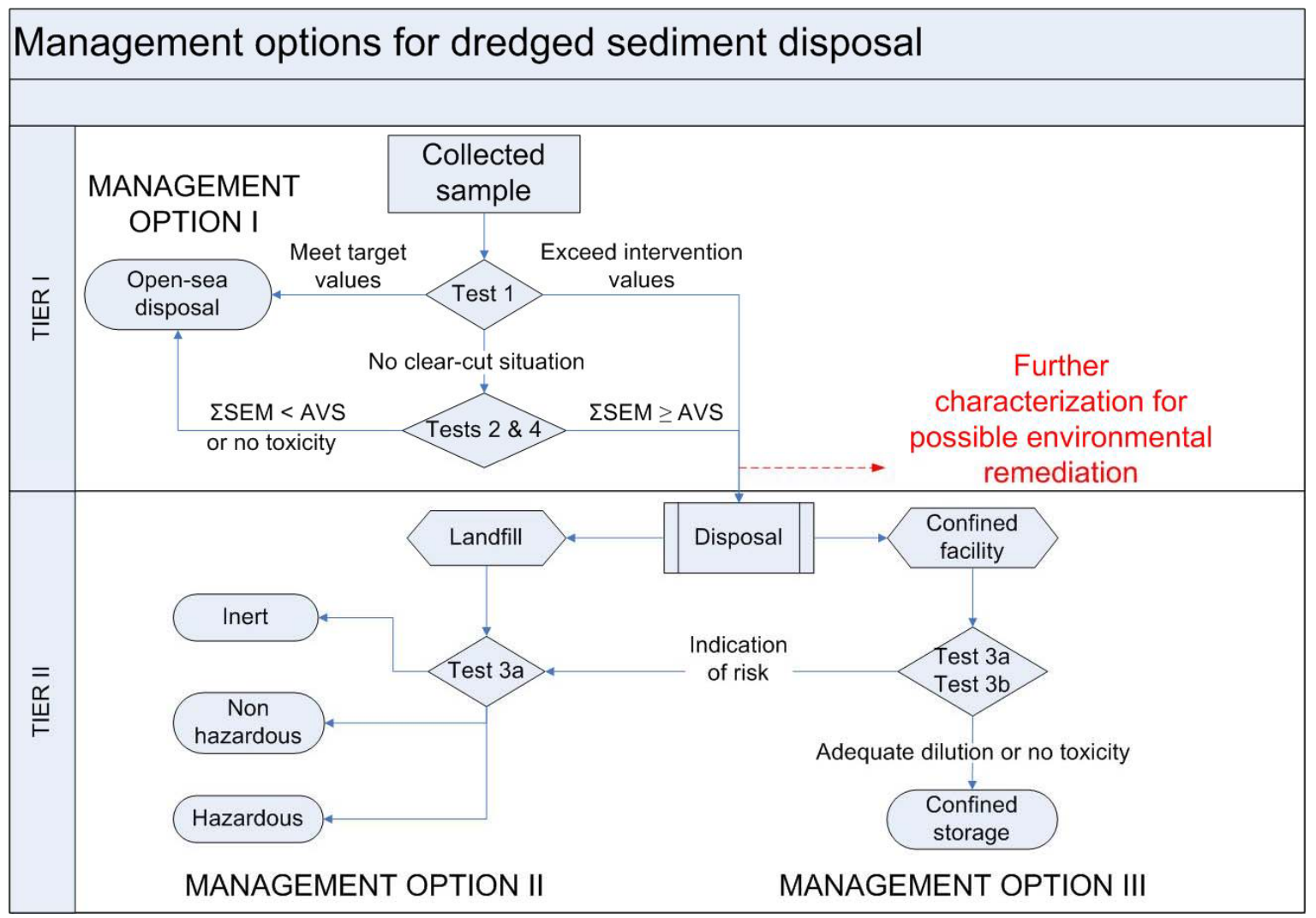

Figure 1. Conceptual model for evaluating management options for the disposal of dredged sediments

\section{MATERIALS AND METHODS}

\subsection{Sample collection and preparation}

Sediment samples were obtained by a grab sampler from nine stations in the port of Piraeus and its vicinity. These stations are systematically monitored by the Organization of port of Piraeus, both for water and sediment quality. The samples were placed in plastic containers fitted with a tight lid and transported to the laboratory for subsequent analyses. The sampling location was recorded by GPS and the sampling depth was measured with a sonar device. Before storage, samples were visually characterized, i.e., for appearance, composition, color, odor and presence of marine organisms.

A portion of each sample was separated in the laboratory for acid volatile sulfides/simultaneously extracted metals (AVS/SEM) analysis and was stored in a closed container under nitrogen gas to avoid oxidation of sulfides. The remaining sample was split in three portions for subsequent analyses in the three matrices tested: collected sediment, sediment pore water and leachate.

Pore water was separated by centrifugation according to standard procedures (WEF, 2002). Separated pore water was then filtered through a 0,45 $\mu \mathrm{m}$ membrane filter.

The leaching test used was the test specified by European Standard EN 12457/1. The dilution used was $2 \mathrm{~L} \mathrm{~kg}^{-1}$, recommended for samples with moisture content higher than $30 \%$. Before the leaching test, sediment samples were passed through a $4 \mathrm{~mm}$ screen to remove coarse 
material. Samples were then dried, the appropriate quantity of distilled water was added and the leaching of constituents was carried out by stirring the samples in a jar test apparatus for 24 hours. Samples were then centrifuged, and the leachate was collected by successive filtrations through glass fiber and membrane filters.

\subsection{Experimental methods}

Characterization tests involved measurements of physical characteristics of collected sediment samples, such as total solids, volatile solids, moisture content and particle size distribution, as well as measurements of total metals in sediment, metals in pore water, metals and other constituents in leachate, toxicity of pore water and leachate, and acid volatile sulfides and simultaneously extracted metals in the acid phase of the AVS/SEM extraction technique. The determination of total dry solids (DS) and moisture content was carried out by APHA method 2540G (APHA, 1992).

For the determination of total metals, collected sediment samples were digested in a microwave oven with the addition of $7 \mathrm{ml}$ nitric acid $60 \%$ and $2 \mathrm{ml}$ hydrofluoric acid $40 \%$, according to EPA Method 3052 (USEPA, 1996). The determination of metals in digested sediment samples, pore water and leachate were performed -with the exception of elements listed belowby flame atomic absorption in a Perkin Elmer AA Analyst 100 apparatus, based on APHA Method 3110 (APHA, 1992). Barium and cadmium were measured by a graphite furnace technique in the same apparatus. Mercury was determined by the hydride method in a Perkin Elmer MHS 10 apparatus and finally arsenic, antimony and selenium in a FIAS, Perkin Elmer AA Analyst 200.

The acid volatile sulfides/simultaneously extracted metals (AVS/SEM) is a toxicity screening test, originally proposed by Allen et al. (1993), based on metal equilibrium partitioning theory. The concentration of AVS measures sulfide species in the sediments, to which metals are bound and become unavailable to microorganisms. AVS is measured by a cold acid extraction technique in a purge and trap apparatus. If the total concentration of metals that are simultaneously extracted by this method is smaller than the AVS concentration, i.e., if $\Sigma$ SEMAVS $<0$, then this is an indication of the absence of potential toxicity, since available forms of metals will be bound to excess sulfides.

Toxicity measurements in pore water and leachate samples were carried out by the luminescent bacteria test in a Lumistox 300 , Microtox ${ }^{\circledR}$ type apparatus. Toxicity is estimated on the basis of luminescence loss (inhibition) of the microorganisms Vibrio fischeri that come to direct contact with the toxic substance for $25 \mathrm{~min}$ in a controlled environment of $2 \%$ salinity and temperature of $15^{\circ} \mathrm{C}$ (Wang et al., 2000).

\section{RESULTS OF CHARACTERIZATION TESTS \\ 4.1. Physical characteristics}

The physical characterization of samples is an initial step required to furnish information on the moisture content, organic content and particle distribution of sediments. Typical results are presented in Table 1 for seven samples from the port of Piraeus (locations 1 through 13) and two from its vicinity (locations 45 and 50 ). Samples from the port of Piraeus had a moisture content in the range of $33-49 \%$, whereas the volatile solids (organic) content was in the range of $2,7-16,7 \%$. Particle size distribution analysis was performed in four of the samples collected from the inner Piraeus port, but were characteristic of the size distribution of samples with both high and low organic content. Samples with a higher organic content had also a high percentage, greater than $73 \%$, of fine material, passing through sieve No $200(74 \mu \mathrm{m}$ opening). These samples had also a higher concentration of contaminants, as discussed in the next section.

\subsection{Chemical and toxicological characterization tests}

Test 1 involves the measurement of the concentration of heavy metals in the collected samples and the comparison with limit values. The results are presented in Table 2 . With the exception of chromium, heavy metal concentrations in all samples were higher than target val- 
ues. Intervention values were exceeded in all locations for one or more metals. More specifically, samples from stations 1, 2, 4, 7 and 10 exceeded intervention values for copper; samples from stations 7 and 10 for lead; and samples from stations 5, 7, 10, 13, 45 and 50 for zinc. (The high concentrations of zinc measured in most of the samples can be considered as the result of sand blasting activities in vessels, which are typical port operations.) Only the sample from station 7 exceeded slightly the intervention value for mercury. None of the samples exceeded the intervention value for nickel. In summary, stations 7 and 10 are considered as the more highly polluted, since more than three elements were found in concentrations exceeding intervention values.

Table 1. Physical characteristics of sediments from Piraeus port and its vicinity

\begin{tabular}{ccccc}
\hline Station & $\begin{array}{c}\text { Total dry solids } \\
\text { (DS) } \\
\text { (g /g sample) }\end{array}$ & $\begin{array}{c}\text { Volatile solids } \\
\text { (\% DS) }\end{array}$ & $\begin{array}{c}\text { Moisture } \\
\text { (\% sample) }\end{array}$ & $\begin{array}{c}\text { Fine material (\%) } \\
<\mathbf{7 4} \boldsymbol{\mu m}\end{array}$ \\
\hline 1 & 0,5101 & $12,03 \%$ & 49,0 & 81 \\
2 & 0,5747 & $7,34 \%$ & 42,5 & 46 \\
4 & 0,5812 & $8,07 \%$ & 41,9 & 38 \\
5 & 0,5830 & $7,02 \%$ & 41,7 & - \\
7 & 0,5596 & $16,65 \%$ & 44,0 & - \\
10 & 0,5244 & $8,31 \%$ & 47,6 & - \\
13 & 0,6140 & $3,06 \%$ & 38,6 & - \\
45 & 0,5602 & $6,98 \%$ & 33,1 & - \\
50 & 0,6715 & $2,73 \%$ & 32,9 & \\
\hline
\end{tabular}

Table 2. Concentration of heavy metals in collected samples (tests 1 and 4 ) and limits relevant to management option I

\begin{tabular}{|c|c|c|c|c|c|c|c|c|c|}
\hline \multirow[b]{2}{*}{ Station } & $\mathrm{Cu}$ & $\mathbf{P b}$ & $\mathrm{Zn}$ & $\mathrm{Ni}$ & $\mathrm{Cr}$ & Cd & $\mathrm{Hg}$ & AVS & ISEM \\
\hline & \multicolumn{7}{|c|}{$\mathrm{mg} \mathrm{kg}^{-1}$} & \multicolumn{2}{|c|}{$\mu \mathrm{mol} \mathrm{g}{ }^{-1}$} \\
\hline 1 & 359,8 & 264,3 & 504,3 & 84,0 & 92,4 & $<20$ & 0,5 & 8,3 & 14,8 \\
\hline 2 & 199,6 & 147,2 & 387,7 & 52,0 & 67,4 & $<20$ & 0,48 & 6,6 & 7,8 \\
\hline 4 & 196,4 & 206,5 & 273,8 & 46,1 & 57,4 & $<20$ & 0,5 & 7,0 & 5,7 \\
\hline 5 & 161,1 & 362,2 & 730,2 & 64,5 & 71,4 & $<20$ & 0,75 & 7,6 & 4,7 \\
\hline 7 & 257,5 & 1628,8 & 768,8 & 46,1 & 59,0 & $<20$ & 10,2 & 5,8 & 8,4 \\
\hline 10 & 291,7 & 724,8 & 827,9 & 61,1 & 74,7 & $<20$ & 1,40 & 7,5 & 10,2 \\
\hline 13 & 129,8 & 377,6 & 922,8 & 44,0 & 67,7 & $<20$ & 0,30 & 5,2 & 5,3 \\
\hline 45 & 58,3 & 135,8 & 815,2 & 136,4 & 107,8 & $<20$ & 0,51 & 3,7 & 3,2 \\
\hline 50 & 127,1 & 261,6 & 824,0 & 42,6 & 52,1 & $<20$ & 0,07 & 8,9 & 4,6 \\
\hline $\begin{array}{c}\text { Target } \\
\text { values }^{\dagger}\end{array}$ & 36 & 85 & 140 & 35 & 100 & 0,8 & 0,3 & & \\
\hline $\begin{array}{c}\text { Intervention } \\
\text { values }^{\dagger}\end{array}$ & 190 & 530 & 720 & 210 & 380 & 12 & 10 & & \\
\hline
\end{tabular}

${ }^{\dagger}$ Netherlands Ministry of Housing Spatial Planning and the Environment (VROM, 2000)

Test 4. Many investigators have shown that the concentration of sulfides is a factor that controls the bioavailability of metals in sediments (McGrath et al., 2002; Fang et al., 2005). Test 4 enables comparisons of AVS concentrations to total SEM concentrations in the collected sediments. If AVS is higher than total SEM, then the potential toxicity risk is considered minimal. The results of the AVS/SEM analysis are also shown in Table 2. In samples from stations 1, $2,7,10$ and $13, \Sigma$ SEM was found higher than the AVS, indicating a potential risk of toxicity.

Tests $2 \mathrm{a}$ and $2 \mathrm{~b}$. The level of heavy metal concentrations in pore waters gives a measure of their bioavailability and potential toxicity. Typical concentrations of heavy metals in pore water are shown in Table 3 for samples from stations 2 and 4 , expressed in $\mu \mathrm{kg}^{-1}$ (mass of metal in pore water per dry mass of the sediment sample containing the pore water). The concentration of metals in pore water is then compared to the metal concentration in sediment samples (given in Table 2) and expressed as a percentage of total mass, which is indicated in Ta- 
ble 3 as "\% of total". Also shown are the results of the toxicity test, expressed as percentage loss of luminescence (inhibition) due to toxicity. It is evident from these results that an extremely small percentage of the total metal concentration, $0,63 \%$ for the most soluble metal $\mathrm{Ni}$, is bioavailable to microorganisms, resulting in the measured zero toxicity. The similarity of results, in terms of the percentage of total mass, obtained in both samples permits the generalization of this conclusion to the other more contaminated samples.

Table 3. Concentration and toxicity of heavy metals in pore water (tests $2 a$ and $2 b$ ).

\begin{tabular}{cccccccccc}
\hline Station & & $\mathbf{C u}$ & $\mathbf{P b}$ & $\mathbf{Z n}$ & $\mathbf{N i}$ & $\mathbf{C r}$ & $\mathbf{C d}$ & $\mathbf{H g}$ & $\begin{array}{c}\text { Inhibition } \\
(\%)\end{array}$ \\
\hline \multirow{2}{*}{2} & $\mu^{\mu \mathrm{kg}^{-1}}$ & 40 & 250 & 37 & 325 & $<44$ & $<8,5$ & $<0,08$ & 0 \\
& $\%$ of total & 0,02 & 0,17 & 0,01 & 0,63 & $<0,06$ & $<0,04$ & $<0,02$ & \\
4 & $\mu^{2} \mathrm{~kg}^{-1}$ & 34 & 510 & 30 & 250 & $<44$ & $<8,5$ & $<0,08$ & 0 \\
& $\%$ of total & 0,017 & 0,25 & 0,01 & 0,60 & $<0,06$ & $<0,04$ & $<0,02$ & \\
\hline
\end{tabular}

Test $3 a$ is a leaching test that measures metals than are easily desorbed from sediments upon contact with water. Leaching results are presented in Table 4 for samples from stations $1,2,5$, and 7 , which had higher contaminant concentrations. Concentrations are expressed both in $\mathrm{mg} \mathrm{kg}^{-1}$ and $\mu \mathrm{g} \mathrm{L}^{-1}$ for easier comparison with limit values. Of the 17 parameters measured in this test, only those pertaining to heavy metals are shown here. The results of the toxicity assessment test, test 3b, are also shown in this table, expressed as percentage inhibition.

Table 4. Leaching test results (tests $3 \mathrm{a}$ and $3 \mathrm{~b}$ ) and limit values pertaining to management options II and III.

\begin{tabular}{|c|c|c|c|c|c|c|c|c|c|c|c|c|}
\hline & \multirow{2}{*}{\multicolumn{6}{|c|}{$\begin{array}{c}\begin{array}{c}\text { Disposal to landfill } \\
\text { (management option II) }\end{array} \\
\mathrm{mg} \mathrm{kg}^{-1}\end{array}$}} & \multicolumn{6}{|c|}{$\begin{array}{l}\text { Disposal to confined facility } \\
\text { (management option III) }\end{array}$} \\
\hline & & & & & & & & & $\mu \mathrm{g} \mathrm{L}^{-1}$ & & & \multirow[b]{2}{*}{ Dmax } \\
\hline & 1 & 2 & 5 & 7 & $A^{\dagger}$ & $\mathbf{B}^{\dagger}$ & 1 & 2 & 5 & 7 & $\mathrm{c}^{\dagger}$ & \\
\hline $\mathrm{Cd}$ & $<0,2$ & $<0,2$ & $<0,2$ & $<0,2$ & 0,03 & 0,6 & $<100$ & $<100$ & $<100$ & $<100$ & 40 & 1 \\
\hline $\mathrm{Cr}$ & $<0,1$ & $<0,1$ & $<0,1$ & $<0,1$ & 0,2 & 4 & $<50$ & $<50$ & $<50$ & $<50$ & 1100 & 1 \\
\hline $\mathrm{Cu}$ & 0,09 & 0,13 & 0,29 & 0,13 & 0,9 & 25 & 45 & 65 & 66 & 146 & 4,8 & 31 \\
\hline $\mathrm{Hg}(\mu \mathrm{g})$ & $<0,2$ & $<0,2$ & $<0,2$ & $<0,2$ & 3 & 50 & 0,1 & 0,1 & 0,1 & 0,1 & 1,8 & 1 \\
\hline $\mathrm{Ni}$ & 0,46 & 0,38 & 0,35 & 0,39 & 0,2 & 5 & 229 & 188 & 193 & 175 & 74 & 3 \\
\hline $\mathrm{Pb}$ & 1,0 & $<0,4$ & 0,9 & 0,5 & 0,2 & 5 & 501 & 200 & 263 & 440 & 210 & 2,4 \\
\hline $\mathrm{Zn}$ & 0,3 & 0,1 & 0,1 & 0,2 & 2 & 25 & 141 & 51 & 70 & 88 & 90 & 1,6 \\
\hline $\begin{array}{c}\text { Inhibition } \\
\%\end{array}$ & & & & & & & 34,2 & 14,4 & 5,0 & 15,1 & & \\
\hline
\end{tabular}

${ }^{\dagger}$ A: Inert material limits and B: non-hazardous material limits (2003/33/EC), C: Acute toxicity saltwater limits (USEPA, 2006)

${ }^{\ddagger}$ Dmax: maximum dilution required to meet limit values for the most contaminated sample $(1=$ no dilution needed)

\section{MANAGEMENT OPTIONS}

\subsection{Tier I assessment}

Tier I assessment is an important management decision step because it will determine whether dredged material can be relocated back to sea or a more expensive management solution, i.e., land disposal, has to be selected. For this assessment, the results of physical characterization and tests 1 and 4 or, alternatively, 1 and 2 are combined. This is necessary since the evidence is not clear-cut, i.e., nearly all elements were found in concentrations higher than target values, but intervention values were exceeded for only some of the elements. A hazard index was calculated from the results of test 1 by dividing each metal concentration by the respective target value and summing up for all metals (Pantazidou et al., 2007). In the case of a sample having a high hazard index, high organic and fine material content and a positive difference $\Sigma$ SEM - AVS $\geq 0$, dredged material is classified as waste and cannot be allowed back to sea. This was the case for samples from stations 1, 7 and 10. 
In the other extreme, i.e., low hazard index, low organic and fine material content and negative difference $\Sigma$ SEM - AVS $<0$, dredged material can be disposed to open sea. Samples 4 , 5,45 , and 50 were classified in this category. Samples 2 and 13 are intermediate cases. However, tests $2 a$ and $2 b$ provide evidence of no toxicity for sediments from station 2 (see Table 3), which hence can be disposed to open sea, whereas, in the absence of further investigations, dredged material from station 13 is classified as waste.

Assessment of the data considered in tier I also evaluates whether some sediments require further characterization, in order to determine the need for possible environmental remediation. Recall that intervention values were exceeded in all stations for one or more metals (Table 2). However, in samples from stations 1, 2, 7, 10 and 13, ¿SEM was also found higher than the AVS (test 4), indicating a potential risk of toxicity. With the exception of location 2 , which tested negative for toxicity (test $2 b$ ), the remaining locations are candidates for further characterization. On the contrary, the negative difference $\Sigma$ SEM-AVS in stations 4, 5, 45 and 50 indicates that there is no need for further characterization, despite the exceedance of the intervention values for copper (station 4) and zinc (stations 5, 45 and 50).

\subsection{Tier II assessment}

In tier II, assessment management options II and III are assessed by combining results from tests $3 \mathrm{a}$ and $3 \mathrm{~b}$. For management option III, disposal to an open confined facility, leachate did not conform to saltwater limit values for $\mathrm{Cu}, \mathrm{Ni}, \mathrm{Pb}$ and $\mathrm{Zn}$ (see Table 4). Moreover, the sample from station 7 requires a very high dilution, 31:1, to meet the limit for copper and, therefore, is excluded from this management option. For the other stations, limit values for copper can be met with a maximum dilution of $14: 1$, which can easily be achieved by discharging supernatant through a short outfall pipe. This dilution will also minimize the low toxicity of the leachate.

Management option II was proven feasible for all stations evaluated. Samples conformed to the limit values for non-hazardous wastes (see Table 4) and, as a result, dredged material can be disposed off in a non-hazardous waste landfill. In this case, the constituents in the leachate will be dealt with by the landfill leachate treatment facilities.

\section{CONCLUSIONS}

This paper presented a decision-making methodology for the management of dredged sediments. The methodology rests on the observation that although sediments from port areas may be contaminated with heavy metals, only a small fraction of the metals is readily bioavailable. Indeed, for the sediment samples from Piraeus port and for the most soluble metal, nickel, the fraction dissolved in pore water was on the order of $0,6 \%$, while the fraction dissolved by leaching with distilled water ranged from 0,7 to $0,8 \%$. Both pore water and leachate showed a minimal toxicity to microorganisms.

The methodology presented in this paper provides a structured system for sediment characterization that allows decisions to be taken regarding ultimate disposal of dredged material. Disposal to open sea proved to be infeasible for the more contaminated sediments from areas with increased shipping activities in the port of Piraeus. Disposal to confined facilities is a good option for sediments with intermediate degrees of contamination. On the other hand, disposal of dredged material to non-hazardous landfill disposal sites was shown to be a viable alternative method of disposal, even for the most contaminated sediments. In addition, the conceptual model includes a "flag" that indicates the need for further characterization, in order to determine whether environmental remediation of the sediments is required; about half of the locations tested fell in the category where further characterization is advisable.

\section{REFERENCES}

Allen H.E., Fu G. and Deng B., (1993), Analysis of acid-volatile sulfide (AVS) and simultaneously extracted metals (SEM) for the estimation of potential toxicity in aquatic sediment, Environmental Toxicology and Chemistry, 12, 1441-1453.

APHA (1992), Standard methods for the examination of water and wastewater, $18^{\text {th }}$ edition, Editors Greenberg A.E. et al., American Public Health Association, Washington DC. 
CEN (2002) EN 12457/1-4 (2002), Leaching - Compliance test for leaching of granular waste materials and sludges: part $1: \mathrm{L} / \mathrm{S}=2 \mathrm{l} / \mathrm{kg}$, particle size $<4 \mathrm{~mm}$, European Committee for Standardization, Brussels.

Chapman P.M. (1990), The Sediment Quality Triad approach to determining pollution-induced degradation, The Science of the Total Environment, 97/98, 815-825.

Chapman P.M. and Anderson J., (2005), A decision-making framework for sediment contamination, Integrated Environmental Assessment and Management, 1(3), 163-173.

EC (2003) 2003/33/EC, European Council Decision of 19 December 2002, Establishing criteria and procedures for the acceptance of waste at landfills pursuant to Article 16 of and Annex II to Directive 1999/31/EC, OJ, L11, 27-49.

Fang T., Li X. and Zhang G., (2005), Acid volatile sulfide and simultaneously extracted metals in the sediment cores of the Pearl River Estuary, South China, Ecotoxicology and Environmental Safety, 61(3), 420-431.

Katsiri A., (2005), Conceptual model for site-specific risk management of contaminated sediments, Proc. of Conf. Management of Coastal zones, November 21-24, Athens, Greece.

McGrath J.A., Paquin P.R. and Di Toro D.M., (2002), Use of the SEM and AVS approach in predicting metal toxicity in sediments, Environmental Fact Sheet 10, ICMM.

Palermo M.R. (1986), Development of a modified elutriate test for predicting the quality of effluent discharged from confined dredged material disposal areas, Technical Report D-86-4, US Army Engineer Waterways Experiment Station, Vicksburg, MS.

Pantazidou M., Kapniaris S., Katsiri A. and Christidis A. (2007), Pollutant trends and hazard ranking in Elefsis Bay, Greece, Desalination, 210, 69-82.

US EPA (1996) Method 3052, Microwave-assisted acid digestion of siliceous and organically based matrices.

US EPA (2006) National Recommended Water Quality Criteria: 2006, http://www.epa.gov/waterscience/criteria/wqcriteria.html\#cmc (accessed 29-1-08).

VROM (2000), Netherlands Ministry of Housing Spatial Planning and the Environment, Circular on target values and intervention values for soil remediation, http://international.vrom.nl/Docs/internationaal/S_I2000.pdf and http://international.vrom.nl/Docs/internationaal/annexS_I2000.pdf (accessed 19-3-08).

Wang C., Yediler A.D., Lienert D., Wang Z. and Kettrup A., (2000), Toxicity evaluation of reactive dyestuffs, auxiliaries and selected effluents in textile finishing industry to luminescent bacteria Vibrio fischeri, Chemosphere, 46, 339-344.

WEF (2002), Handbook on Sediment Quality, Water Environment Federation, Alexandria, VA. 